\title{
Incorporating measurable outcomes into the highway design process: a case study to demonstrate highway safety improvements
}

\author{
C. E. Carrigan \& M. H. Ray \\ RoadSafe LLC, USA
}

\begin{abstract}
Highway crashes result in the death of approximately 41,000 people per year in the United States alone. Roughly one-third of these fatal crashes are with fixed objects along the roadside. An obvious solution for improving roadside safety would be to remove or shield all fixed objects along the roadside. This would certainly decrease the number of fatal and serious injury crashes but could result in the removal of many roadside trees and the installation of hundreds of miles of roadside barrier, leaving an unacceptable aesthetic environment to road users which would also cost many millions of dollars.

Removing trees entirely or installing hundreds of miles of roadside barrier, therefore, is not a viable option. A better approach is to understand the highway characteristics that make some locations more prone to crashes and treat the most hazardous locations. It is the objective of this paper to present an example highway design problem which considers design alternatives using a benefit/cost analysis of alternatives to determine the preferred alternative and to minimize all project related costs (i.e., design, construction, right-of-way, etc.) including costs related to crashes.
\end{abstract}

Keywords: highway safety, cost/benefit analysis.

\section{Introduction}

Achieving and maintaining a competitive edge over other regions or nations has been linked to the size and quality of the available transportation network, however, any transportation network has risks associated with it. These risks include the frequent crashes on the various modes of transportation. Highway crashes result in the death of approximately 43,000 people per year in the United 
States alone.[1] Balancing the benefits to society of transportation network improvements with risks such as crashes has seldom been explicitly considered during design in the United States. The reduction or increase in construction costs, however, are often juggled and judged by individual engineers with little guidance regarding the safety provided through design standards resulting in each potential improvement or design alternative being evaluated differently. The American Association of State Highway and Transportation Officials (AASHTO) publishes a variety of highway design guidelines to assist highway designers in the development and assessment of highway designs. These guidelines include A Policy on Geometric Design of Highway and Streets [2] (i.e., the Green Book) and the Roadside Design Guide (RDG) [3]. Additional guidelines and policies also used include the Manual of Uniform Traffic Control Device [4] (MUTCD) published by the Federal Highway Administration (FHWA) and the Highway Capacity Manual [5] (HCM2000) published by the Transportation Research Board (TRB).

Highway designers often rely on these established design standards and warrants as a means for producing a "safe" design. These warrants are simple to follow and require little knowledge of the project area. Each design element is considered independent of the other elements of the road which impact the overall performance of the road.

AASHTO recently released a new publication called the Highway Safety Manual (HSM). The HSM provides highway designers with a tool to quantify and compare the expected relative crash risk of various highway design alternatives.

In addition to the established design standards presently used by highway planners and designers and those recently published in the HSM, there are many statistical models which have been developed to predict where crashes may occur along the road and the roadside. Some have been used for decades in the RDG. The use of the models presented in the HSM and the RDG during planning and design in conjunction with established design standards will bring the issue of maximizing highway safety to the forefront of the highway design process. An informed discussion of the true cost of a project can be assessed over the design life of a highway with the economic impacts of safety also a factor in the analysis. It is the objective of this paper to present an example highway design problem which considered roadside design alternatives using a benefit/cost analysis of alternatives. This analysis includes a review of safety benefits and costs of each alternative.

\section{Background}

Motor vehicles crashes cost society more than $\$ 230$ billion annually. During an average day, American roads experience approximately 117 fatalities. Thirty percent of these fatalities are people under the age of twenty-five. In total, this amounts to a societal cost of $\$ 630$ million lost per day [6].

Some costs are less obvious and are a result of decisions made during the early stages of designing a new roadway or upgrading and existing roadway. For 
example, a decision to route an existing stream through a culvert and provide a headwall protected by a guardrail may appear to be the most cost effective decision to the designer concerned with minimizing construction costs, however, when the potential for vehicles striking the guardrail during the project life is considered, the possible societal loss through the cost of the crashes and increased maintenance costs throughout the design life of that section of road can result in costs not considered by the designer. If the safety costs of decisions are included when considering alternatives, the choice of a guardrail and head-wall may not be as economically attractive as moving the culvert intake farther from the road such that a guardrail is no longer necessary.

\subsection{Benefit/Cost analysis for highways}

When conducting a benefit-cost analysis, it is important to calculate a benefitcost ratio $(\mathrm{B} / \mathrm{C})$ for each feasible alternative with benefits in the numerator and project costs in the denominator. The resulting $\mathrm{B} / \mathrm{C}$ for each alternative should be listed in descending order to allow for a comparison of the ratios, not just benefits or project costs. Project benefits are defined "....as an increase in wellbeing or a decrease in the use of real resources," [7] therefore, benefits include a reduction in crash related costs. Project costs include the design, construction, and maintenance costs associated with the improvement. While each element of a project's benefit can be quantified using different units, each benefit is converted to a common monetary unit of measure for comparison with project costs. The $\mathrm{B} / \mathrm{C}$ ratio, therefore, is unitless.

Understanding the cost of crashes and possible reduction of those costs (i.e., benefits) and the project costs (e.g., design, construction, and maintenance) is important when calculating the $\mathrm{B} / \mathrm{C}$ for each improvement alternative and conducting a $\mathrm{B} / \mathrm{C}$ analysis to determine which alternative is the preferred alternative.

\subsubsection{Project costs}

Conducting a $\mathrm{B} / \mathrm{C}$ analysis requires a reasonable understanding of all the project costs. Project costs are easily recognized as the design, construction and maintenance costs of an improvement alternative, however, they also include environmental mitigation and right-of-way (ROW) costs associated with the preferred alternative. Impacts to the environment, available ROW and their associated costs are routinely evaluated when considering improvement alternatives as these costs can be considerable for projects with alignment or cross-section changes. Construction costs, however, are generally the largest project related cost considered by the programming agencies and are used as the benchmark for other costs during the planning stage of a project.

The Washington Department of Transportation (WSDOT) preformed a survey of highway agencies within the United States in 2002 to better understand all project related costs and to gauge how WSDOT costs relate to other States. WSDOT found the average construction cost within the United States is \$2.3 Million per lane mile of highway. This figure excludes “...right of way, preconstruction environmental compliance, and construction environmental 
compliance and mitigation." [8] These exclusions are quite variable by project and region, let alone State.

Design costs, or the costs related to preparing a project for construction, are generally accepted to be approximately ten percent of the construction costs of the project. The WSDOT study found that design costs range from four to 20 percent with an average of 10 percent.

\subsubsection{Cost of crashes}

Measuring the costs of crashes may seem challenging. In fact, there are many different indexes that have been developed which measure just that. The "Red Book" measures crash costs as those that directly impact the user, including:

- "Injury, morbidity, and mortality of the user;

- Injury, morbidity and mortality of those other than the user who must be compensated;

- Damage to the property of the user;

- Damage to the property of others" [7].

FHWA uses the willingness-to-pay concept, which has been documented by economists who observed that people "...express how much well-being they get out of something by demonstrating willingness-to-pay for it" [7]. Willingness-topay, however, is a misnomer and the figures actually represent how much a person actually pays. When considering crash costs, this concept would translate to "... how much people actually pay to reduce safety risks" [9]. A study updated by FHWA in 1994 relates this concept to the KABCO scale commonly used by Police to describe the severity of a crash. Each letter of the scale equals a different severity (e.g., $\mathrm{K}$ for a fatal injury and $\mathrm{O}$ for a property damage only crash) and results in a different willingness-to-pay. Table 1 summarizes the findings of the 1994 update.

Table 1: Comprehensive costs (1994 Dollars) police-reported crashes [9].

\begin{tabular}{|c|c|cr|}
\hline SEVERITY & DESCRIPTOR & $\begin{array}{c}\text { COST PER } \\
\text { INJURY }\end{array}$ \\
\hline K & Fatal & \multicolumn{2}{|c|}{$\$ 2,600,000$} \\
\hline A & Incapacitating & $\$$ & 180,000 \\
\hline B & Evident & $\$$ & 36,000 \\
\hline C & Possible & $\$$ & 19,000 \\
\hline PDO & $\begin{array}{c}\text { Property } \\
\text { Damage Only }\end{array}$ & \multicolumn{2}{|c}{} \\
\hline
\end{tabular}

The National Highway Traffic Safety Administration (NHTSA) conducted research in 2000 and determined the economic cost of motor vehicle crashes in the United States was $\$ 230.6$ billion, “... which represents the present value of lifetime costs for 41,821 fatalities, 5.3 million non-fatal injuries, and 28 million 
damaged vehicles, in both police-reported and unreported crashes" [11]. The contribution of various factors to this assessment are summarized in Figures 1 and 2. These costs do not include the consequences of these events and "... should not, therefore, be used alone to produce cost-benefit ratios" [11].

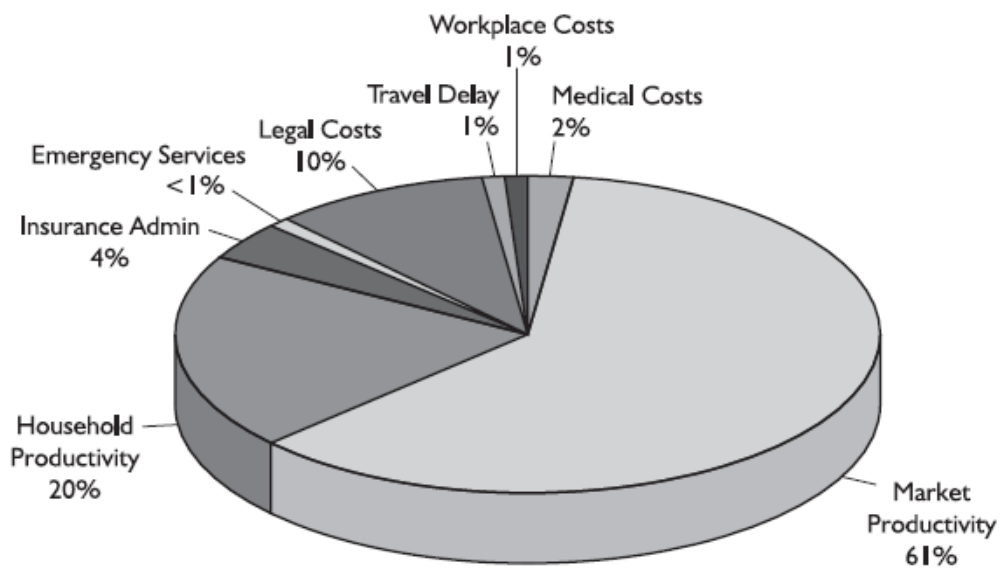

Figure 1: Components of total costs, fatalities [11].

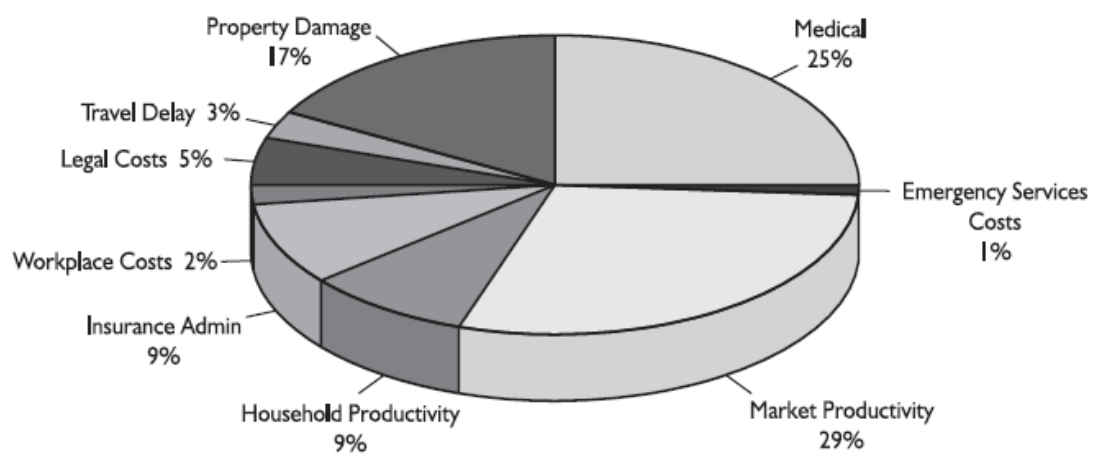

Figure 2: $\quad$ Components of total costs, non-fatal injuries [11].

The costs are presented in Table 2, using the Abbreviated Injury Scale (AIS). The AIS is used to classify the severity of injuries, as follows: AIS 1 = Minor; AIS 2 = Moderate; AIS 3 = Serious; AIS 4 = Severe; AIS $5=$ Critical; and AIS 6 $=$ Fatal. The injury rating may not be the same throughout the body, therefore, the most serious injury dictates the scale ranking. 
Table 2: $\quad$ Economic costs (2000 Dollars) of reported and un-reported crashes [11].

\begin{tabular}{|l|r|}
\hline Severity & Cost per Injury \\
\hline PDO & $\$ 2,532$ \\
\hline MAIS0 & $\$ 1,962$ \\
\hline MAIS1 & $\$ 10,562$ \\
\hline MAIS2 & $\$ 66,820$ \\
\hline MAIS3 & $\$ 186,097$ \\
\hline MAIS4 & $\$ 348,133$ \\
\hline MAIS5 & $\$ 1,096,161$ \\
\hline Fatal & $\$ 977,208$ \\
\hline
\end{tabular}

In summary, crash costs can be estimated many different ways, which results in many different dollar amounts. Each index has an appropriate use. When considering benefits to society, it's accepted that the FHWA willingness-to-pay concept is most appropriate and should be used in combination with an appropriate crash modeling technique which can capture crash severity, as discussed in the following section.

\section{Example problem}

Using state-of-the-art tools presently available supplemented by software developed by this research, [12] engineers can evaluate the potential for crashes given the combined influence of the horizontal, vertical and cross-sectional geometry of the proposed improvements. Several different alternatives can be compared and a preferred alternative is selected.

This analysis will consider four alternatives in addition to the baseline alternative. These alternatives are as follows:

- Alternative 0: Existing conditions.

- Alternative 1: Meets all Green Book and RDG warrants with full depth reconstruction of the roadway.

- Alternative 2: Maintains existing geometry; resurfaces the roadway, improves sideslopes and clear zones.

- $\quad$ Alternative 3: Maintains existing geometry and side slopes; resurfaces the roadway and improves clear zones.

- Alternative 4: Maintains existing geometry and clear zones; resurface the roadway and improves sideslopes.

The horizontal alignment was evaluated using the speed consistence models available within the IHSDM software. The horizontal alignment has good speed consistency. Existing clear zones are noted in Table 3. The Clear Zone (CZ) offset is measured from the Baseline. 
Table 3: $\quad$ Existing clear zones.

\begin{tabular}{|c|c|c|c|}
\hline $\begin{array}{c}\text { Start STA } \\
(\mathrm{m})\end{array}$ & $\begin{array}{c}\text { Start STA } \\
(\mathrm{ft})\end{array}$ & $\begin{array}{c}\text { Existing CZ } \\
\text { offset }(\mathrm{m})\end{array}$ & $\begin{array}{c}\text { Existing } \\
\text { CZ offset } \\
(\mathrm{ft})\end{array}$ \\
\hline $11+250$ & $369+09$ & 5.9 & 19 \\
\hline $11+851$ & $388+80$ & 10.9 & 36 \\
\hline $12+765$ & $418+79$ & 12.0 & 40 \\
\hline
\end{tabular}

The existing horizontal geometry satisfies Green Book warrants, however, the vertical geometry does not. Three segments exceed the recommended maximum grade of eight percent. Additionally, this design does not include any passing zones. Some would consider the Green Book standards not applicable for Alternatives two, three, and four, because these alternatives may be considered maintenance projects.

The crash costs of these five alternatives were evaluated over the project life using the software created for this research [12]. This software used data from published literature to relate the severity of specific hazards with the speed of impact. Currently, this is expressed by a Severity Index (SI) per unit of speed. For example, the SI for W Beam strong post is 0.312848 per mile per hour. The SI for a $200 \mathrm{~mm}$ (4 inch) diameter tree is 0.13502 per mile per hour. This would indicate, at the same speed, a crash with $\mathrm{W}$ Beam would be more severe then with a small diameter tree. An SI does not exist in the literature for a tree line. Tree lines are quite prevalent in the New England region and function as a longitudinal hazard, but are not designed to redirect the vehicle such as a crashtested barrier should.

This example problem has clear zones which are defined by tree lines. The hazard has been modeled as a linear hazard, similar to $\mathrm{W}$ Beam, not a point hazard like a single tree. This means that every time a vehicle leaves the road and the hazard is within the vehicle swath. It is more likely that the vehicle would hit the tree line hazard a certain percentage of the time and other times get wedged between the trees or even pass between trees and brush without a collision. It is also possible the vehicle will stop or regain control before it hits the trees. Additional research is needed in this area to properly identify the severity of tree line crashes and the probability of impacting the hazard given the density of trees; however, this modeling technique can be used in the interim. In order to determine the crash severity of the tree line at the back of the clear zone, an SI was calibrated using the 2005 crash data.

A review of the 2005 crash data revealed four injury crashes and one fatal crash within the project limits. These crashes would cost society $\$ 3,320,000$ in 2005 using the FHWA willingness to pay crash values. Several model runs resulted in a predicted crash existing conditions (Alternative zero) crash cost of $\$ 3,143,637$. This prediction was made with an SI equal to 0.097214 , which is approximately $72 \%$ of the small tree SI. The calibrated SI was used to predict 
the crash costs of the other alternatives under consideration. The resulting crash costs are shown in the first column of Table 4.

The estimated construction costs of each alternative are also presented in Table 4. The Green Book suggests that Rural Collects have a 20 year design life. Some highway agencies may program an improvement project based on the available construction funding. Using this mentality, Alternative three would be the preferred alternative. Recall this alternative would increase the clear zone to the prescribed twenty-eight feet and resurface the road. Some highway agencies will only consider the alternative which meets all design warrants, therefore alternative one would be the preferred alternative.

As discussed above, the societal cost of crashes should also be considered in a cost-benefit analysis of alternatives with the costs equal to the construction investment and the benefits equal to the reduction in crash costs. The calculated present worth crash costs are shown in figure 3, considering a $4 \%$ discount rate and a 20 year design life. A cost-benefit analysis of each alternative compared with the existing conditions (alternative zero) is presented in Table 4. The alternative with the highest cost-benefit ratio would be the preferred alternative. Alternative three, increasing the clear zones while resurfacing the roadway appears to be the most cost-beneficial alterative and should proceed to final design and construction. This analysis assumes the country drainage (i.e., simple open ditches) remains. If room is not available within the existing ROW, one may consider alternative four which maintains the clear zone while flattening the ditches.

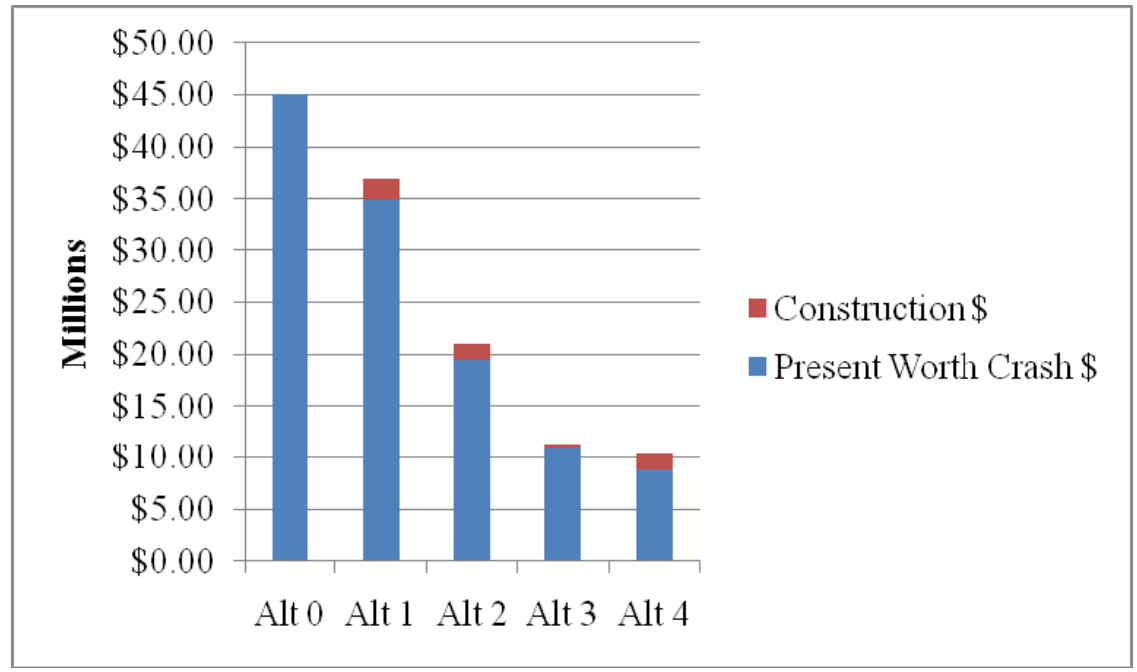

Figure 3: Present worth crash costs and construction costs for each alternative. 
Table 4: Cost-benefit analysis of alternatives.

\begin{tabular}{|l|r|r|r|l|}
\hline Alt & $\begin{array}{c}\text { Annual } \\
\text { Crash Cost }\end{array}$ & $\begin{array}{c}\text { Present Worth } \\
\text { Crash \$ }\end{array}$ & \multicolumn{1}{c|}{\begin{tabular}{c}
\multicolumn{1}{c|}{ Const. } \\
Cost
\end{tabular}} & \multicolumn{1}{c|}{$\begin{array}{c}\text { B/C to } \\
\text { Alt 0 }\end{array}$} \\
\hline 0 & $\$ 3,320,000$ & $\$ 45,118,800$ & $\$ 0$ & \\
\hline 1 & $\$ 2,572,919$ & $\$ 34,965,969$ & $\$ 2,006,200$ & 0.37 \\
\hline 2 & $\$ 1,425,953$ & $\$ 19,378,701$ & $\$ 1,566,200$ & 1.21 \\
\hline 3 & $\$ 798,534$ & $\$ 10,852,077$ & $\$ 506,200$ & 4.98 \\
\hline 4 & $\$ 646,812$ & $\$ 8,790,175$ & $\$ 1,566,200$ & 1.71 \\
\hline
\end{tabular}

A more detailed analysis of the preferred alternative is needed within problem segments to try to reduce encroachment rates. This can be accomplished through minor changes to the alignments and cross-section while using the tools previously discussed to analyze the changes. This effort should be focused on only the problem segments to limit increases in expected funding needs.

Following the completion of the analysis of a preferred design alternative, the project will then proceed to final design and documentation, bidding and construction.

\section{Summary and conclusion}

Motor vehicle crashes claim approximately 41,000 lives each year. Roughly 37 percent of these fatal crashes are with fixed objects along the roadside [13]. An obvious solution for improving roadside safety would be to remove or shield all fixed objects along the roadside. This would certainly decrease the number of fatal and serious injury crashes but could result in the removal of many roadside trees and the installation of hundreds of miles of roadside barrier to shield items such as utility poles, leaving an unacceptable aesthetic environment to road users and costing millions of dollars. Removing trees entirely or installing hundreds of miles of roadside barrier, therefore, is not a viable option. A better approach is to understand the highway geometrics that make some roadside objects more potentially harmful than others and to develop strategies for identifying these most hazardous objects. The process demonstrated herein helps to identify problem segments which need additional attention and elevate needless spending on the overdesign of whole highways.

\section{References}

[1] Garber, N.J., Hoel, L.A., "Traffic and Highway Engineering, Fourth Edition," Cengage learning, Toronto, ON, 2009.

[2] "A Policy on Geometric Design of Highways and Streets", $4^{\text {th }}$ edition", American Association of State Highway and Transportation Officials (AASHTO), Washington D.C., 2001. 
[3] Roadside Design Guide, 3rd edition with 2006 Chapter 6 Update, American Association of State Highway \& Transportation Officials, Washington, DC.

[4] Manual on Uniform Traffic Control Devices, 2003, U.S. Department of Transportation-Federal Highway Administration, Washington, DC.

[5] Highway Capacity Manual (HCM 2000), 2000 edition, Transportation Research Board-National Research Council, Washington, DC.

[6] FHWA Safety, http://safety.fhwa.dot.gov/facts/index.htm, April 17, 2008

[7] "User Benefit Analysis for Highways Manual," American Association of State Highway and Transportation Officials (AASHTO), Washington D.C., 2003.

[8] http://www.wsdot.wa.gov/biz/Construction/pdf/I-C_Const_Cost.pdf, accessed September 11, 2009

[9] http://www.fhwa.dot.gov/legsregs/directives/techadvs/t75702.htm, accessed August 23, 2009

[10] Meyer, M.D., "Crashes vs. Congestion-What's the Cost to Society?," Cambridge Systematics, Inc., 4800 Hampden Lane, Suite 800, Bethesda, Maryland 20814, March 5, 2008

[11] Blincoe, L., Seay, A., Zaloshnja, E., Miller, T., Romano, E., Luchter, S., Spicer R., "The Economic Impact of Motor Vehicle Crashes, 2000," Report No. DOT HS 809 446, online version, http://wwwnrd.nhtsa.dot.gov/Pubs/809446.PDF, accessed November 1, 2009

[12] Carrigan, C.E., "Development of a Performance-based Highway Design Process: Incorporating Safety Considerations into Highway Design," $\mathrm{PhD}$ Dissertation, Worcester Polytechnic Institute, May, 2010

[13] National Highway Traffic Safety Administration (NHTSA), Traffic Safety Facts 2007, DOT HS 811 002, National Center for Statistics and Analysis, USDOT, 2008, Washington, DC 20590. 